\title{
Thermal decomposition kinetics of sodium carboxymethyl cellulose: Model-free methods
}

\author{
Naushad Ahmad a, Rizwan Wahab b,* and Suliman Yusuf Al Omar b \\ a Department of Chemistry, King Saud University, Riyadh 11451, Kingdom of Saudi Arabia \\ b Department of Zoology, King Saud University, Riyadh 11451, Kingdom of Saudi Arabia \\ *Corresponding author at: Department of Zoology, King Saud University, Riyadh 11451, Kingdom of Saudi Arabia. \\ Tel.: +966.53.6023284. Fax: +966.12.6068536. E-mail address: rwahab@ksu.edu.sa (R. Wahab).
}

\section{ARTICLE INFORMATION}

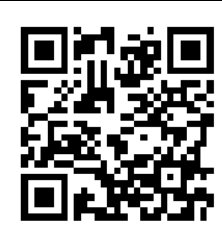

DOI: $10.5155 /$ eurjchem.5.2.247-251.971

Received: 15 November 2013

Received in revised form: 27 December 2013

Accepted: 27 December 2013

Online: 30 June 2014

\section{KEYWORDS}

\section{Kinetics}

Cellulose

Thermal reactions

Thermal degradation

Isoconversional methods

Sodium carboxymethyl cellulose

\section{Introduction}

The interest in thermal stability of polymers increased considerably in the last few decades because it is an important parameter that determines the application as well as the processing conditions [1]. One of the frequently observed kinetic mechanisms of thermal degradation of polymers is depolymerization monomer molecules which are detached one by one from the chain ends. Among various biopolymers, cellulose is the most abundant biopolymer on earth, which is being increasingly considered as fuel or source for renewable energy [1,2]. Thermal decomposition of cellulose has been widely studied for the past several years. The decay of cellulose can also be used thermally for the production of chemicals and bio-oils [3]. Moreover, due to its availability, low cost and biodegradability, cellulose is widely used to reinforce polymeric materials and to design a huge array of novel biopolymers and biocomposites. It has been reported that the source of cellulose and its composition greatly affect to its pyrolysis. In spite of the large amount of work performed by many investigators during last decade, the actual understanding of the kinetics of thermal degradation of cellulose and its derivatives, sodium carboxymethyl cellulose, is still largely unexplained. Thermogravimetric analysis (TGA) is a widely used technique in this area [4]. It is useful for the thermal characterization of both inorganic and organic materials, including polymers. It provides quantitative results regarding the loss of mass of a sample as a function of increasing temperature or time [5]. Moreover, thermogravimetric measurements provide basic information regarding the thermal properties of the material and its composition. The first derivative thermogravimetry can be used to investigate the differences among TG curves [6]. In 1956, Stamm has been reported the kinetics for the degradation of cellulose in inert atmosphere and calculated the activation energy $109 \mathrm{~kJ} / \mathrm{mol}$ [7]. More recently, Dahiya et al. reported kinetics information for degradation of cellulose by using two methods, model-fitting and a model-free methods, and found to be activation energy in the range of 156.5-166.5 $\mathrm{kJ} / \mathrm{mol}$ and $\ln \mathrm{A}$ of 20-23 1/min and suggested F1 mechanism [8].

Sodium carboxymethyl cellulose is a representative cellulose derivative with carboxymethyl groups $\left(-\mathrm{CH}_{2}-\mathrm{COONa}\right)$ bonded to some of the hydroxyl groups on cellulose backbone. It is water soluble anionic cellulose derivative which contains a hydrophobic polysaccharide backbone and many hydrophilic carboxyl groups, and hence shows amphiphilic characteristics [9-11]. Due to its special physical, chemical and biological properties it has extensive applications in the food industry [12], agriculture [13], pharmacy, medicine [14,15] and waste 
water treatment [16]. Indeed, it is a biocompatible and biodegradable polymer [17] whose degradation pathway has been studied by various methods [18-20]. In view of the new applications of this environmental friendly polymer further studies shall be developed to determine its thermal stability as well as to allow a better understanding on the mechanistics and kinetics aspects involved in the thermal degradation of the polymer. With this aim, the present investigation focuses on the thermal stability and kinetic parameters of SMC. The obtained results were calculated by applying three model free methods to dynamic thermogravimetric data. To the best of our knowledge, very limited research study has been done on cellulosic materials pyrolysis using these methods.

\section{Experimental}

Sodium carboxymethyl cellulose, $\mathrm{T}_{\mathrm{m}}=274^{\circ} \mathrm{C}, \mathrm{Mw}=$ $\sim 90,000$, viscosity $=400-800 \mathrm{cP}$ purchased from Aldrich chemical corporation and was used as research objects. The thermal analysis (TG/DTG) was performed using TA instruments, SDT Q-600. The experiments were performed with the utmost care in order to minimize heat and mass transfer phenomena so that kinetic parameters more representative of the forward reaction are obtained. For each experiment, $10.0 \mathrm{mg}$ of the sample was loaded into alumina crucibles $\left(\alpha-\mathrm{Al}_{2} \mathrm{O}_{3}\right)$ in the heating zone of the TGA. An empty pan was used as reference. The thermal scanning mode ranges from ambient temperature to $700^{\circ} \mathrm{C}$ at a programming heating rates of $10,15,20$ and $30{ }^{\circ} \mathrm{C} / \mathrm{min}$ in dynamic helium atmosphere with a gas flow of $100 \mathrm{~mL} / \mathrm{min}$.

\section{Kinetic studies}

Kinetic investigations of polymeric materials have been carried out using numerous techniques to analyze the data. Most often, TGA is the experimental method of choice and the only technique to be explored here. TGA involves keeping polymer on a microbalance within a furnace and monitoring the mass loss of the polymer in isothermal and non-isothermal conditions.

The kinetics of thermal transformation of a solid state chemical reaction is generally described by the general equation 1.

$v=(d \alpha / d t)=k(T) f(\alpha)$

where $\alpha$ is degree of conversion/reacted fraction, $t$ is the time, $T$ is the process temperature and $k(T)$ is a temperaturedependent constant and $f(\alpha)$ is the reaction kinetic model, accounts for the reaction rate dependence on $\alpha$. The kinetic model is an algebraic expression, which is usually associated with a physical model that describes the kinetics of the solid state reaction. $k(T)$ is normally approximated by the Arrhenius equation (2),

$k(T)=A \exp (-E / R T)$

where $A, E, R$, and $T$ are the pre-exponential factor, the apparent activation energy, the universal gas constant $(R=$ $8.314 \mathrm{~J} / \mathrm{mol} . \mathrm{K}$ ), and the absolute temperature, respectively. For a dynamic thermogravimetric process, Equation 1 can be modified using the definition of the constant heating rate, $\beta=$ $d T / d t$, as in the equation 3.

$(d \alpha / d t)=(A / \beta) f(\alpha) \exp (-E / R T)$

This is a fundamental equation of solid kinetics. One of the few difficulties encountered in using Equation 3 is the determination of the $E$ of a reaction without having any previous knowledge about the reaction model. There are several methodologies to evaluate the thermal degradation kinetics. Here iso-conversional methods, also known as "model free", are used for determining the activation energy as a function of the reacted fraction without any previous assumption on the kinetic model fitted by the reaction. These methods are based on the assumption that the reaction mechanism is independent of the heating program, using multiple heating rates. Among the several available "model free" methods used to calculate the activation energy of the thermal decomposition process, in this study the KissingerAkahira-Sunose (KAS), Flynn-Wall-Ozawa (FWO) and Friedman methods were applied.

The KAS method [21,22] is based on the Coats-Redfern approximation, which is based on the Equation 4.

$\ln \left(\frac{\beta}{T^{2}}\right)=\ln \frac{A R}{E g(\alpha)}-\frac{E}{R T}$

In Equation 4, the kinetic parameters $(A, E)$ of each species during the pyrolysis of poltmer particles are determined from the slope of $\ln \left[\beta / T^{2}\right]$ versus $1 /$ T peak and the intercept of the fitted plot with respect to $\ln \left[\beta / T^{2}\right]$.

The FWO method was developed independently by Flynn and Wall [23] in the USA and Ozawa [24] in Japan. FWO method is one of the model-free integral methods that can determine the activation energy without knowledge of reaction order. It involves measuring the temperatures corresponding to the fixed values of conversion $(\alpha)$ from the experiments at different heating rates $(\beta)$. Equation 3 is integrated using the Doyle approximation [25].

The result of the integration after taking logarithms is

$\ln \beta=-1.052(E / R T)+[\ln (A E / R)-\log (g(\alpha))-5.33](5)$

where $\beta, A, E$ and $T$ have the known meanings.

It is used to determine the activation energy for given values of conversion. The activation energy for different conversion values can be calculated from an $\ln \beta$ versus $1 / T$ plot, the pre-exponential factor was also determined from the intercept of the plots at each conversion level.

Friedman method [26] is probably the most general of the differential techniques and utilizes the following natural logarithmic equation 6 .

$\ln \left(\beta \frac{d \alpha}{d t}\right)=\ln A+\ln f(\alpha)-\frac{E}{R T}$

It directly leads to $(-E / R)$ for a given value of $\alpha$ by plotting the term $\ln [\beta \mathrm{d} \alpha / \mathrm{dt}]$ versus $1 / T$ at any certain conversion level.

\section{Results and discussion}

\subsection{Nonisothermal decomposition behavior of SMC}

Thermal decomposition of SMC was studied by the nonisothermal conditions and their mass losses, onset temperature of degradation $\left(\mathrm{T}_{\text {onset }}\right)$, maximum degradation rate temperature $\left(\mathrm{T}_{\max }\right)$, mass loss percentage at $\mathrm{T}_{\max }$, the extent of reaction at maximum reaction rate $\alpha_{\max }$, and residue mass loss at different heating rates were evaluated, listed in Table 1. It clearly shows that the onset, maximum peak degradation temperatures, moss loss at $\mathrm{T}_{\max }$ and maximum degradation rate are increased in a linear fashion as the heating rates $(\beta)$. This temperature shift might be due to heat transfer effect [27]. On the other hand, the residual char yield decreased as the heating rate increased might be due to rapid pyrolysis [28], which needs very high heating rate and short residence time for the degraded products. However, there is no significant difference in the onset and maximum peak degradation temperatures of SMC. 
Table 1. Results of TG/DTG traces of SMC in helium atmosphere at different heating rates.

\begin{tabular}{|c|c|c|c|c|c|c|}
\hline $\begin{array}{l}\text { Heating rate } \\
\left({ }^{\circ} \mathrm{C} / \mathrm{min}\right)\end{array}$ & $\begin{array}{l}\mathrm{T}_{\text {onset }} \\
\left({ }^{\circ} \mathrm{C}\right)\end{array}$ & $\begin{array}{l}\mathrm{T}_{\max } \\
\left({ }^{\circ} \mathrm{C}\right)\end{array}$ & $\begin{array}{l}\alpha_{\max } \\
(\mathrm{wt} \% / \mathrm{min})\end{array}$ & $\begin{array}{l}\text { Mass loss at } \mathrm{T}_{\max } \\
(\%)\end{array}$ & $\begin{array}{l}\text { Total mass loss } \\
(\%)\end{array}$ & $\begin{array}{l}\text { Residue } \\
(\%)\end{array}$ \\
\hline 10 & 267.19 & 288.07 & 13.46 & 33.70 & 65.53 & 34.47 \\
\hline 15 & 278.63 & 294.88 & 20.53 & 34.06 & 67.89 & 33.77 \\
\hline 20 & 280.06 & 298.27 & 27.86 & 34.31 & 66.22 & 32.12 \\
\hline 30 & 288.39 & 309.04 & 40.52 & 38.93 & 68.44 & 31.52 \\
\hline
\end{tabular}

Table 2. Kinetic parameters of SMC at different conversion degrees determined by model-free isoconversonal methods.

\begin{tabular}{|c|c|c|c|c|c|c|}
\hline \multirow[t]{2}{*}{ Conversion \% } & \multicolumn{2}{|l|}{ KAS } & \multicolumn{2}{|l|}{ FWO } & \multicolumn{2}{|l|}{ Friedman } \\
\hline & E (kJ/mol) & $\ln A(1 / \mathrm{min})$ & E (kJ/mol) & $\ln A(1 / \mathrm{min})$ & $\mathrm{E}(\mathrm{kJ} / \mathrm{mol})$ & $\ln A(1 / \min )$ \\
\hline 10 & 26.57 & 5.66 & 30.42 & 2.28 & 32.57 & 2.35 \\
\hline 20 & 138.84 & 29.89 & 140.79 & 24.01 & 143.48 & 25.88 \\
\hline 30 & 154.51 & 32.82 & 155.82 & 27.83 & 159.22 & 29.13 \\
\hline 40 & 166.29 & 34.45 & 167.16 & 29.83 & 171.07 & 31.39 \\
\hline 50 & 172.16 & 35.45 & 172.89 & 30.31 & 177.02 & 32.20 \\
\hline 60 & 430.74 & 75.78 & 441.42 & 69.17 & 443.57 & 71.84 \\
\hline Average & 181.51 & 35.67 & 184.75 & 30.57 & 187.82 & 32.13 \\
\hline
\end{tabular}

The shapes of the SMC mass loss curves (Figure 1a) do not change with the variations of the heating rate under experimental conditions. This phenomenon is characteristic of the surface particles of polymer, which displaces at higher heating rates and primarily causes degradation of SMC due to increase of surface area. The thermal events are only slightly dislocated to higher temperature values with higher heating rates. This phenomenon is characteristic of the equipment, which detects the events in higher temperatures with higher heating rates [29].
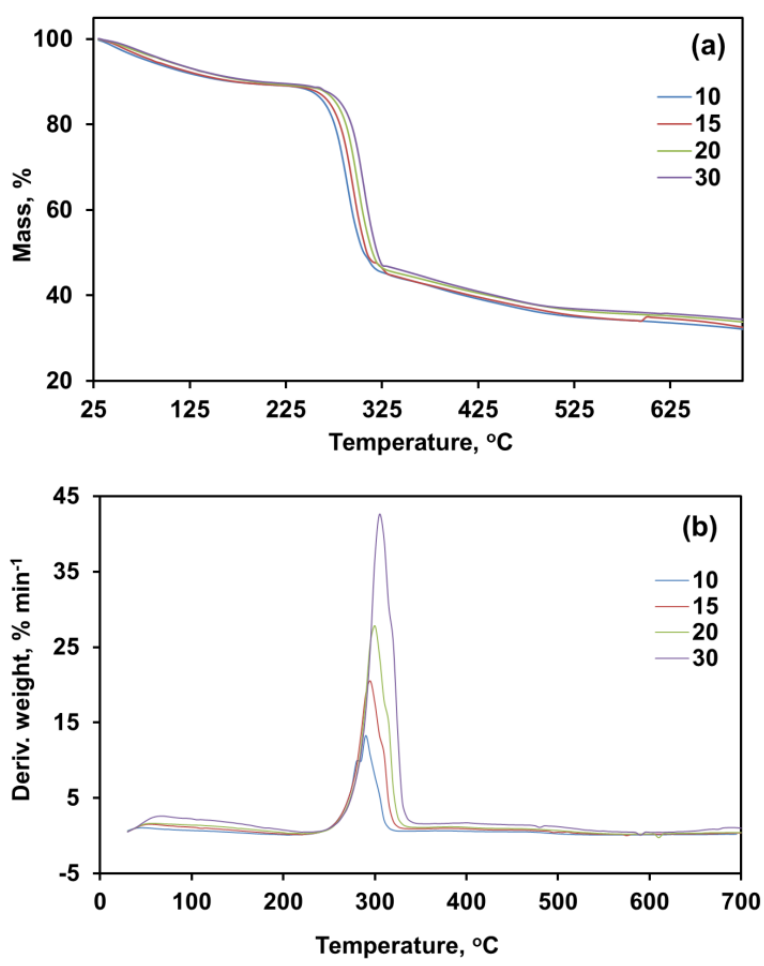

Figure 1. (a) Mass curves profile and (b) Derivative mass curves for SMC in helium atmosphere at different heating rates.

The thermal degradation process of the SMC takes place as a three steps of mass losses. During pyrolysis, volatile compounds are generated, consumed, and released. The volatile materials produced by intermediate reactions on the exterior as well as interior of the SMC would pyrolyzed above $100{ }^{\circ} \mathrm{C}$ during the TGA run. Therefore, the first step of thermal degradation could be assigned to the evolution the water/ alcohol content in the SMC, small peak observed in the DTG curves (Figure 1b). The second major thermal degradation occurs in a short interval of temperature, between 250 and 375 ${ }^{\circ} \mathrm{C}$. This step could be associated with breaking the bond associated to functional groups and weak groups in the chain and unfastening of cellulose chain into smaller unit $[29,30]$. The last degradation step of SMC is not observed with a maximum peak in the DTG curve. This step could be associated with thermal degradation of dehydrated products of the carbon structure include a wide range of alkanes, alkenes, dienes and aromatic cyclization of carbonaceous char residue.

The first derivative thermogravimetry (DTG) is commonly used to detect the thermal stability and rate of mass loss, which cannot be observed by only the mass loss curve (Figure 1b). The data in table 1 disclose that the increase of the heating rate leads to an increase in the maximum peak temperatures [29]. The maximum mass loss rate $\left(T_{\max }\right)$ for SMC has been occurred at $288.07,294.88,298.27$ and $309.04{ }^{\circ} \mathrm{C}$ at heating rates of 10 , 15,20 and $30^{\circ} \mathrm{C} / \mathrm{min}$.

\subsection{Nonisothermal Kinetic Investigation of SMC}

In order to contribute comprehensive role of the heating rates on the thermal degradation of SMC, kinetic parameters of the overall weight loss calculated by applying the KAS, FWO, and Friedman methods (Equations 4, 5 and 6, respectively). The results are summarized in Table 2 for the six conversion ratios. The mean values of the activation energy $(E)$ and preexponential factor $(\ln A)$ were determined from the arithmetic average and the natural logarithmic average, respectively. As regarding the activation energy as a function of extent of conversion, it demonstrates the linear dependence on the extent of conversions ranging between 10 and $60 \%$ for the SMC. Figure 2a-c show isoconversional linear fitting plots of $\ln \left[\beta / T^{2}\right]$ versus $1000 / T$, $\ln \beta$ versus $1000 / T$ and $\ln [\beta d \alpha / d t]$ versus $1000 / T$ for the SMC at fixed value for $\alpha=10-60$ of the three methods, KAS (a), FWO (b) and Friedman (c), respectively. Three different regions in the isoconversional curves are observed. These regions correspond to each step of the thermal degradation process seen in the TG/DTG curves of the SMC. The irregularity in the spacing of the isoconversional curves is related with the breaking of chain with the different levels of energy occurring at the same time as well as the several steps and different mechanisms of the complex thermal degradation [31-33]. The slope of the lines allows calculating the activation energy listed in Table 2. The process of calculating the activation energy well depends on the experimental conditions and the applied isoconversional methods. 

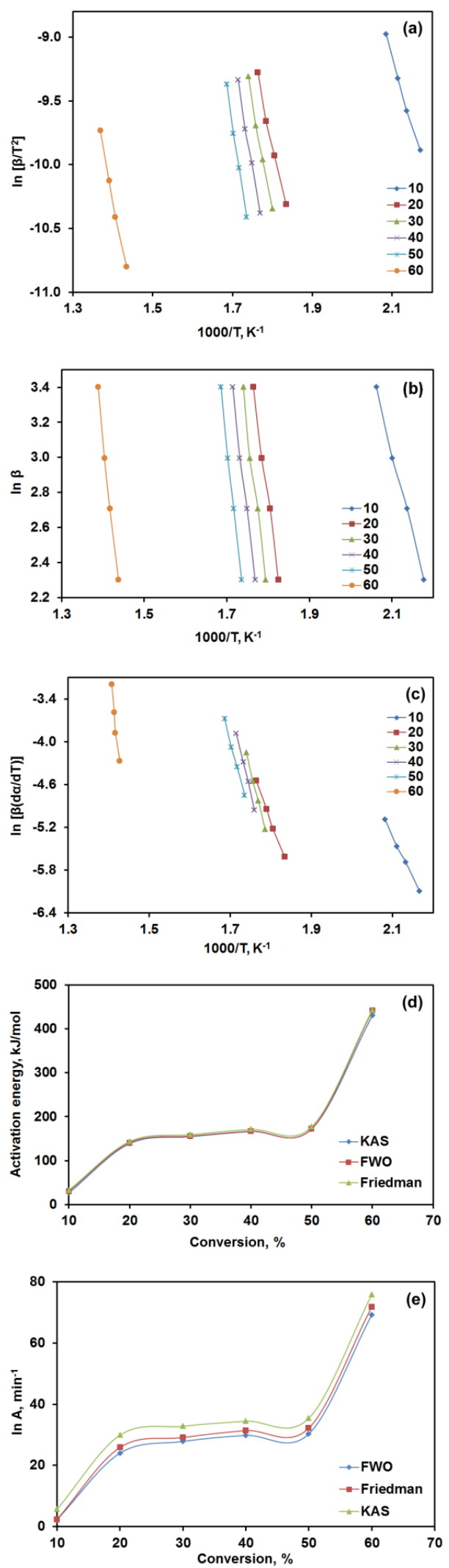

Figure 2. Isoconversional plots for the thermal decomposition of the SMC based on (a) KAS method (Equation 4), (b) FWO method (Equation 5); (c) Friedman method (Equation 6), (d) Activation energy values calculated by the KAS, FWO and Friedman and (e) Pre exponential factor calculated by the KAS, FWO and Friedman methods at varying degree of conversion.
The activation energies were calculated by the above three equations and are plotted against each conversion degree (Figure 2d). The apparent activation energy for SMC varies between 26.57 and $443.57 \mathrm{~kJ} / \mathrm{mol}$ and it increases along the increase in fraction of mass conversion but the activation energy remains almost constant between 20 and $50 \%$ conversion and drastically attains a maximum at $\sim 60 \%$ conversion. The lower activation energy observed for SMC may be due to the presence of impurities/water. A broad range of the activation energy of SMC could be attributed to the linkage scissions in the functional groups followed by the scissions of linkage on the chain. These processes occurred via radical chain mechanism by decreasing of the barrier energy for the decomposition process $[34,35]$. In general, the dependence of $E$ on the fraction of mass conversion is associated with the occurrence of parallel, consecutive, and irreversible reactions on the thermal degradation process of the polymers [36].

The comparison of activation energies with the application of above three methods, it is observed that values of activation of Friedman method are slightly higher than the values determined by FWO method which in turn higher than KAS method.

The average values of $E$ for KAS $(181.51 \mathrm{kj} / \mathrm{mol})$ and FWO $(184.75 \mathrm{kj} / \mathrm{mol})$ methods obtained in the range $10-60$ conversion level are also lower than average values of $E$ obtained for Friedman (187.82 kj/mol). Some of the differences observed between the values of $E$ obtained using various linear integral methods (KAS and FWO) can be assigned to the different approximations of the temperature integral. However, all applied methods reveal the same trend on $E$ as regards the range of $\alpha$ evaluated, which indicate that the chosen isoconversional methods are reasonable. In agreement to Maciejewski et al., [32], the kinetic description of the solid state reactions is influenced not only by the complicated nature of the process but also by the method of calculation and heating rates.

The dependence of isoconversional intercepts (FWO, Friedman and KAS) on the degree of conversion $(\alpha)$ is presented in inset Figure 2e. It can be seen that the isoconversional intercept values show the significant dependence on the degree of conversion. It can be seen that that the values of pre-exponential factor regularly increases with an increasing degree of conversion. The highest average values of isoconversional intercepts for KAS, FWO, and Friedman methods are found for KAS and lowest for FWO method. These pre-exponential values are the measure of the collision frequencies.

\section{Conclusions}

A brief review of various methods of the kinetics of thermally stimulated solid-state reactions has been given. In this study, the pyrolysis of SMC was investigated using TG and a model-free method. The results showed that values of both $E$ and $\ln A$ obtained from nonisothermal methods are in good agreement. The variation in activation energy at lower $(\alpha=10)$ and higher conversion $(\alpha=60)$ due to the different mechanisms of thermal degradation of SMC at lower conversion (dehydration) and higher conversion (crosslinking and aromatic cyclization of char residue). The constant activation energy ( $\alpha=20-50)$ seems to indicate that pyrolysis is governed by the slowest step in the multistep decomposition process.

\section{Acknowledgements}

This project was supported by Deanship of Scientific Research, College of Science Research Center, King Saud University, Riyadh, Kingdom of Saudi Arabia.

\section{References}


[1]. Saddawi, A.; Jones, J. M.; Williams, A.; Wojtowicz, M. A. Energ. Fuel. 2010, 24, 1274-1282.

[2]. Souza, D.; Castillo, T. E.; Rodriguez, R. J. S. J. Therm. Anal. Calorim. 2012, 109(3), 1353-1364.

[3]. Mohan, D.; Pittman, C. U.; Steele, P. H. Energ. Fuel. 2006, 20, 848889.

[4]. Antal, M. J. J.; Varhegyi, G. Ind. Eng. Chem. Res. 1995, 34, 703-717.

[5]. Abidi, N.; Hequet, E.; Cabrales, L.; Gannaway, J.; Wilkins, T.; Wells, L. W. J. App. Polym. Sci. 2008, 107, 476-486.

[6]. Abidi, N.; Hequet, E.; Ethridge, D. J. App. Polym. Sci. 2007, 103, 34763482.

[7]. Stamm, A. J. Ind. Eng. Chem. 1956, 48, 413-417.

[8]. Dahiya, J. B.; Kumar, K.; Hagedorn, M. M.; Bockhorn, H. Polym. Int. 2008, 57, 722-729.

[9]. Majewicz, T. G.; Podlas, T. J. Cellulose ether. In Encyclopedia of chemicaltechnology, $4^{\text {th }}$ Ed., New York: Wiley, 1966, Vol. 5, pp. 545547.

[10]. Majewicz, T. G.; Podlas, T. J.; Kroschwitz, J. I. Kirk-Othmer. Cellulose Ethers, Kroschwitz, J. I. (Editor), Kirk-Othmer Concise Encyclopedia of Chemical Technology, Wiley-Interscience, 2005.

[11]. Hui, L. O.; Kumar, R. N.; Rozman, H. D.; Noor, M.; Azemi, M. Polymers 2005, 59, 57-69.

[12]. Muzzarelli, R. A. A. Carbohydr. Polym. 1966, 29, 309-316.

[13]. Vander, P.; Varum, K. M.; Domard, A.; El-Geddari, N. E.; Moerschbacher, B. Plant Physiol. 1998, 118, 1353-1359.

[14]. Peluso, G.; Petillo, O.; Ranieri, M.; Santin, M.; Ambrosio, L.; Calabro, D.; Avallone, B.; Balsamo, G. Biomaterials 1994, 15, 1215-1220.

[15]. Gerentes, P.; Vachoud, L.; Doury, J.; Domard, A. Biomaterials 2002, 23, 1295-1302.

[16]. Despond, S.; Espuche, E.; Domard, A. J. Polym. Sci. Part B 2001, 39, 3114-3127.

[17]. Kumar, G.; Bristow, J. F.; Smith, P. J.; Payne, G. F. Polymer. 2000, 41, 2157-2168

[18]. Holme, H. K.; Foros, H.; Pettersen, H.; Dornish, M.; Smidsrod, O. Carbohydr. Polym. 2001, 46, 287-294.

[19]. Piotr, U.; Von Clemens, S. J. Chem. Soc. Perkin Trans. 2000, 2, 20222028.

[20]. Shao, J.; Yang, Y.; Zhong, Q. Polym. Degrad. Stab. 2003, 82, 395-398.

[21]. Kissinger, H. E. Anal. Chem. 1957, 29, 1702-1706.

[22]. Akahira, T.; Sunose, T. Chiba Inst. Technol. 1971, 16, 22-31.

[23]. Flynn, J. H.; Wall, L. A. J. Polym. Sci. Part C-Polym. Lett. 1966, 4, 323328.

[24]. Ozawa, T. Bull. Chem. Soc. Japan 1965, 38, 1881-1882.

[25]. Doyle, C. D. Nature 1965, 207, 290-291.

[26]. Friedman, H. L. J. Polym. Sci. C 1964, 6, 183-195.

[27]. Volker, S.; Rieckmann, Th. J. Anal. Appl. Pyrol. 2002, 62, 165-177.

[28]. Lede, J. Ind. Eng. Chem. Res. 2002, 39, 893-898.

[29]. Gallagher, P. K. Thermogravimetry and Thermomagnetometry, in Handbook of Thermal Analysis and Calorimetry, Ed. Brown, M. E. Elsevier Science B. V., Amsterdam, 1998, 1, pp. 225-278.

[30]. Gongwer, P. E.; Arisawa, H.; Brill, T. B. Combust Flame. 1997, 109, 370-381.

[31]. Brown, M. E.; Maciejewski, M.; Vyazovkin, S.; Nomen, R.; Sempere, J.; Burnham, A.; Opfermann, J.; Strey, R.; Anderson, H. L.; Kemmler, A. R.; Keuleers, J.; Desseyn, H. 0.; Chao-Rui, L.; Tang, T. B.; Roduit, B.; Malek, J.; Mitsuhashi, T. Thermochim. Acta 2000, 355(1-2), 125-143.

[32]. Maciejewski, M. Thermochim. Acta 2000, 355, 145-154.

[33]. Vyazovkin, S.; Wight, A. C. Annu. Rev. Phys. Chem. 1997, 48, 125-149.

[34]. Lomakin, S. M.; Rogovina, S. Z.; Grachev, A. V.; Prut, E. V.; Alexanyan, Ch. V. Thermochim. Acta 2011, 521, 66-73.

[35]. Chrissafis, K.; Paraskevopoulos, K. M.; Bikiaris, D. N. Polym. Degrad. Stab. 2006, 91, 60-68. 